\title{
Determinantes sociais, objetivos do desenvolvimento sustentável e os desafios para os profissionais da área de saúde no Brasil
}

\author{
Social determinants, objectives of sustainable development and the challenges for \\ health professionals in Brazil
}

Determinantes sociales, objetivos del desarrollo sostenible y los desafíos para los profesionales del área de salud en Brasil

Monteiro, Maria Inês ${ }^{1}$

Como citar este editorial: Monteiro MI. Determinantes sociais, objetivos do desenvolvimento sustentável e os desafios para os profissionais da área da saúde no Brasil. J. nurs. health. 2018;8(3):e188311

Os Objetivos do Desenvolvimento Sustentável (ODS) ou Sustainable Development Goals (SDG), são 17, cuja meta é o futuro melhor e sustentável para todos, abrangendo diferentes domínios e têm sido amplamente divulgadas desde sua aprovação na Assembleia geral da Organização das Nações Unidas (ONU), no final de 2015. ${ }^{1}$ Atualmente, tanto no Brasil quanto no exterior (União Europeia), o financiamento à pesquisa das instituições federais e estaduais, bem como de organizações não governamentais (ONG), como a Fundação Bill e Melinda Gates nos Estados Unidos, e as charities no Reino Unido têm, em geral, determinado que os projetos a serem financiados atendam parte dos ODS.

Os determinantes sociais têm papel fundamental para que a meta global de equidade em saúde seja conquistada. Marmot, que coordenou a Comissão dos Determinantes Sociais, na década passada, compara as recomendações do documento Fair society, healthy lives, ${ }^{2}$ com as conclusões da Swedish National Review e aponta as similaridades entre as mesmas: "dar a cada criança o melhor início possível na vida; educação e habilidades; emprego e condições de trabalho; renda e recursos econômicos; habitação e condições do bairro; e fatores de saúde (...)". 3:29 Destaca ainda dois tópicos "controle, influência e participação", e cuidados de saúde equitativos.

Entre os tópicos mencionados destaco a educação, que abrange as diferentes fases da vida e as condições de trabalho. O aprendizado contínuo é essencial não somente para a vida no trabalho, como também para o desenvolvimento pleno de outras facetas da vida. Na atualidade as carreiras são longas, com duração aproximada de quatro décadas, com possibilidade de expansão para cinco, devido, entre outras causas, ao aumento na expectativa de vida em diversos países, em especial nos de economia de renda média e alta. Os trabalhadores de saúde atuando em diferentes níveis de complexidade, no Brasil, como saúde comunitária, atenção

\footnotetext{
${ }^{1}$ Enfermeira. Doutora em Enfermagem. Líder do Grupo de Estudos e Pesquisa em Saúde e Trabalho. Pesquisadora do CNPq - PQ2. Universidade Estadual de Campinas (UNICAMP). E-mail: inesmon@unicamp.br http://orcid.org/0000-0002-6004-8378
} 


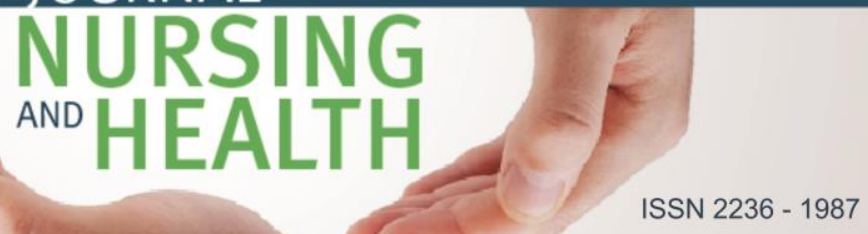

hospitalar, empresas, comunidade, ONG, entre outros, têm papel fundamental para atingirmos as metas/recomendações mencionadas acima.

Nesta perspectiva é fundamental que o ambiente de trabalho seja saudável e favorável à permanência dos profissionais de saúde, que com as mudanças globais, assumem novos desafios. Destaco entre eles a imigração e o movimento global de refugiados, que traz em seu cerne a ampliação do cuidado na perspectiva cultural. Outro aspecto é a ampliação do cuidado tendo como referência a prática baseada em evidências, além da incorporação de novas tecnologias no cuidado em saúde.

Outro desafio para os profissionais de saúde está diretamente relacionado às mudanças na sociedade, como a expectativa dos clientes/usuários/família referentes à 'customização' de seu atendimento, baseada em suas características pessoais e necessidades. A health literacy dos usuários também têm impacto na efetividade do atendimento prestado.

As instituições públicas e privadas são fundamentais na preservação da capacidade para o trabalho dos trabalhadores, propiciando ambiente de trabalho saudável e seguro, assim como o acesso à educação continuada. Com isto, o trabalhador pode manter-se ativo e saudável no trabalho e, após a aposentadoria o que, em geral, propicia o aumento da produtividade e, indiretamente, é benéfico para a competitividade do país.

\section{REFERÊNCIAS}

1 United Nations. Sustainable Development Goals [Internet]. 2015 [cited 2018 Oct 17]. Available from: https://www.un.org/sustainabledevelopment/sustainabledevelopment-goals/

2 Marmot M. Fair society, healthy lives: strategic review of health inequalities in England post-2010 [Internet]. London: The Marmot review; 2010 [cited 2018 Oct 23]. Available from: www.parliament.uk/documents/fair-society-healthy-lives-fullreport.pdf.

3 Marmot M. Nordic leadership and global activity on health equity through action on social determinants of health. Scand j public health [Internet]. 2018 [cited 2018 Nov 06];46(Suppl20):27-9. Available from: http://journals.sagepub.com/doi/full/10.1177/1403494818756795 